\title{
Antioksidan Gümüş Nanoparçacıkların Sentezlenmesi, Karakterizasyonu ve Kataliz Uygulamaları
}

\author{
Synthesis of Antioxidant Silver Nanoparticles, Characterization and Catalysis Applications
}

\author{
Muradiye ŞAHİN ${ }^{1 D}$, Illkay Hilal GÜBBÜK² D \\ ${ }^{1}$ Selçuk Üniversitesi, Fen Bilimleri Enstitüsü Selçuklu, 42075, Konya, Türkiye. \\ ${ }^{2}$ Selçuk Üniversitesi, Fen Fakültesi, Kimya Bölümü, Selçuklu, 42075, Konya, Türkiye.
}

$\ddot{\mathrm{O} z}$

Metal nanoparçacıklar hem kuantum büyüklüğü etkisine ilişkin optik ve elektronik özellikleri hem de optoelektronik, optik, kataliz, tıp, kimyasal/biyokimyasal sensörler gibi alanlarda umut vaat eden uygulamaları nedeniyle uzun yıllar boyunca yoğun bir şekilde çalışılmaktadır. Bu çalışmada gümüş nanoparçacıklar (AgNPs), tarçın, keçiboynuzu, zencefil ve zerdeçal antioksidan özütleri kullanılarak başarıyla sentezlenmiştir. Sentezlenen antioksidan gümüş nanoparçacıklar UV-VIS spektroskopisi, SEM-EDX ve FTIR ile karakterize edilmiştir. Sentezlenen AgNPs'ler boyaların (Metil Oranj, Metilen Mavisi ve Rodamin B) sodyum borhidrür $\left(\mathrm{NaBH}_{4}\right)$ ile indirgenmesinde katalizör olarak uygulanmıştır. Bozunma reaksiyonları için kinetik parametreler (k) hesaplanmış ve yaklaşık 6-10 dakika antioksidan gümüş nanoparçacıklarına maruz kalmalarıyla boyaların etkili bir şekilde parçalanmasını sağlamıştır.

Anahtar Kelimeler: Gümüş nanoparçacık, kataliz, bozunma, antioksidan, boya.

\begin{abstract}
Metal nanoparticles have been extensively studing for many years because of both their optical and electronic properties related with the quantum magnitude effect and their promising applications in such areas as optoelectronics, optics, catalysis, medicine and chemical/biochemical sensors. In this study silver nanoparticles (AgNPs) were successfully synthesized by using antioxidants from cinnamon, carob, ginger and turmeric extracts. Thus synthesized antioxidant silver nanoparticles were characterized by UV-VIS spectroscopy, SEM-EDX and FTIR. The synthesized AgNPs were acted as a catalyst to degradation of dyes (methyl orange, methylene blue and rhodamine B) with sodium borohydride $\left(\mathrm{NaBH}_{4}\right)$. Kinetic parameters $(k)$ for the degradation reactions have been calculated and synthesized antioxidant silver nanoparticles were effectively degrading the dyes nearly 6-10 min. of exposure time.
\end{abstract}

Keywords: Silver nanoparticle, catalysis, degradation, antioxidant, dye.

\section{I.GİRIŞ}

Hızlı endüstrileşme ve nüfus artışı ile birlikte hava, su ve toprak kirliliği olarak sınıflandırılan çevre kirliliği, dünya için büyük bir sorun olup su kirliliği bu sınıfın en büyük kısmını oluşturmaktadır. Birleşmiş Milletlerin 2017 Dünya Su Gelişim Raporuna göre, temiz suların tahmini \%16’sı özellikle endüstriyel atıklarla kirlenmektedir, bu nedenle dünyadaki temiz suyun azalması söz konusudur. Su kaynaklarını kirleten en önemli sebeplerden birisi ise günümüzde yaygın olarak kullanılan organik boyar maddelerdir. Boyar maddelerin arıtımı için, son otuz yıldan beri çeşitli fiziksel, kimyasal ve biyolojik metotlar kullanılmaktadır. Boyar maddelerin atık sulardan arıtılması için geliştirilen teknolojiler arasında bu maddelerin tamamen parçalanmasını sağlayan katalitik yöntemler son yıllarda öne çıkmaktadır. Bu yöntemlerde katalitik etkisi artırılmış maddeler kullanılarak hazırlanan hibrit malzemeler her geçen gün daha dikkat çeker hale gelmektedir. Nanoparçacıklar geniş yüzey alanına sahiptirler ve bu özellikleri onların katalizör olarak kullanılmasını sağlar. Bu çalışmada, yüksek katalitik aktiviteye sahip metal nanoparçacıkların organik boyaların katalitik bozunması için kullanımı amaçlanmıştır. 
Metal nanoparçacıkların sentezi fiziksel ve kimyasal birçok yöntemle [elektrokimyasal indirgeme, yaş kimyasal yöntemler (sol-jel, kimyasal çöktürme, mekano kimyasal yöntem), buhar yöntemleri (soy gaz yoğuşturma, anlık eritme ve yoğunlaştırma, sprey dönüşüm), fotokimyasal indirgeme v.b.] gerçekleştirilebilmektedir [1]. Ancak farklı tekniklerle başarıyla sentezlenmelerine rağmen bu teknikler pahalıdır ve genellikle zararlı kimyasallar içermektedir. Yeşil kimyaya ve diğer biyolojik proseslere karşı artan ilgi bilim insanlarını basit, uygun fiyatlı, biyomedikal ve farmakolojik uygulamalara uyumlu ayrıca geniş bir yelpazede ticari üretime elverişli olma gibi birçok avantaja sahip çevre dostu bir nanoparçacık sentezi yaklaşımına yönlendirmiştir [2]. Metal nanoparçacıkların yukarıda bahsedilen klasik sentez yöntemleri karmaşık ve çok pahalı olması, toksik madde kullanımı gerektirmesi, farmakolojik ve biyomedikal uygulamalara uygun olmaması gibi birçok dezavantaj içermektedir. Yeşil (green) sentez ise basit ve ekonomik oluşu, toksik madde kullanımı gerektirmemesi, farmakolojik ve biyomedikal uygulamalara uygun, geniş yelpazede ticari üretime elverişli olması gibi avantajlarından dolayı günümüzde sıkça kullanılan bir yöntem haline gelmiştir. Metal nanoparçacıkların yeşil sentezinde mantar, maya, bakteri, bitki özütleri gibi maddeler indirgen olarak kullanılmaktadır $[1,3,4]$.

Gümüş, birçok indirgenme reaksiyonunu çok etkili bir şekilde katalize edecek iyi bir katalitik ajan olarak bildirilmiştir [5-7], ancak gümüş nano parçacıkların kimyasal sentezi de çevresel bir tehlikeye yol açar. Bu nedenle son birkaç yılda, gümüş nano parçacıkların bitki kaynaklı biyolojik olarak sentezi, ekonomik ve çevre dostu olması nedeniyle daha fazla önem kazanmaktadır. Gümüş nanoparçacıkların katalitik aktivitelerinin yanı sıra iyi bir antibakteriyel özelliğe de sahip oldukları bildirilmiştir $[8,9]$. Bu nedenlerle, bu çalışmada gümüş nano parçacıklarını yeşil sentez yöntemi ile indirgeyici ajan olarak tarçın, keçiboynuzu, zencefil ve zerdeçal antioksidanlarını kullanarak sentezledik. Böylelikle hem su kirliliğini gidermek hem de daha hijyenik ve daha sağlıklı sular elde etmeyi hedefledik.

Son olarak seçilen çevre için zararlı olan ve kanserojen boyaların bozundurulması çalışması yapıldd. Bu amaçla metil oranj, metilen mavisi ve rodamin B gibi kullanımı yaygın boyalarla çalışıldı. Boyaların indirgenip indirgenmediği
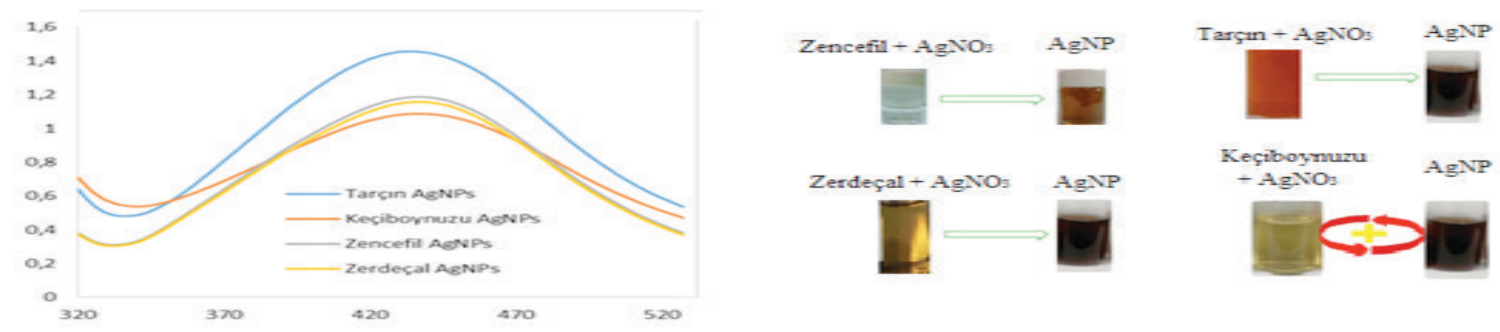

Şekil 1. Gümüş nanoparçacıkların UV-Visible ölçüm değerleri ve gözlenen renk değişimleri. 


\subsection{Kataliz Uygulamalart}

Antioksidan bitki özütleri kullanılarak sentezlenen gümüş nanoparçacıklar rodamin $\mathrm{B}$, metil oranj ve metilen mavisinin indirgenmesinde $\mathrm{NaBH}_{4}$ ile birlikte kullanılarak çok kısa

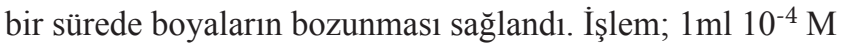

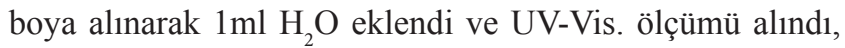
daha sonra $1,5 \mathrm{ml} \mathrm{NaBH}_{4}$ ve $0.5 \mathrm{ml}$ nanoparçacık eklenerek 2'şer dk. aralıklarla ölçüm yapılarak gerçekleştirildi.

\section{III.BULGULAR VE TARTIŞMA}

\subsection{Karakterizasyon}

Keçiboynuzu, tarçın, zencefil ve zerdeçal ile bunların özütleri kullanılarak sentezlenen gümüş nanopaçacıkların FTIR spektrumları Şekil 2'de karşılaştırmalı olarak gösterilmektedir. $3274 \mathrm{~cm}^{-1}$ dalgaboyunda $-\mathrm{OH}$ piki gözlenmektedir. $1766 \mathrm{~cm}^{-1}$ dalgaboyunda görülen pik $\mathrm{C}=\mathrm{C}$ çift bağlarına veya aromatik halkalara $1650 \mathrm{~cm}^{-1}$ dalgaboyunda görülen pik karboksil grubunda $\mathrm{C}=\mathrm{O}$ gerilmesine karşılık gelmektedir. $1026 \mathrm{~cm}^{-1}$ de görülen pik aminlerin - $\mathrm{CN}$ - gerilmesine karşılık gelmektedir. $1307 \mathrm{~cm}^{-1}$ de görülen IR piki geminal metil ile ilişkilendirilebilir.

Bu sonuçlar kıyaslandığında $\mathrm{C}=\mathrm{O}$ pik şiddetinin azaldı $\breve{1}$ ve daha düşük dalga sayısında piklerin oluştuğu görülmüştür. $\mathrm{Bu}$ sonuç AgNP oluşumu üzerine $\mathrm{COOH}$ grubuna sahip bileşiklerin etkisi olduğunu düşündürmektedir, benzer bulgulara literatürde de rastlanmaktadır.
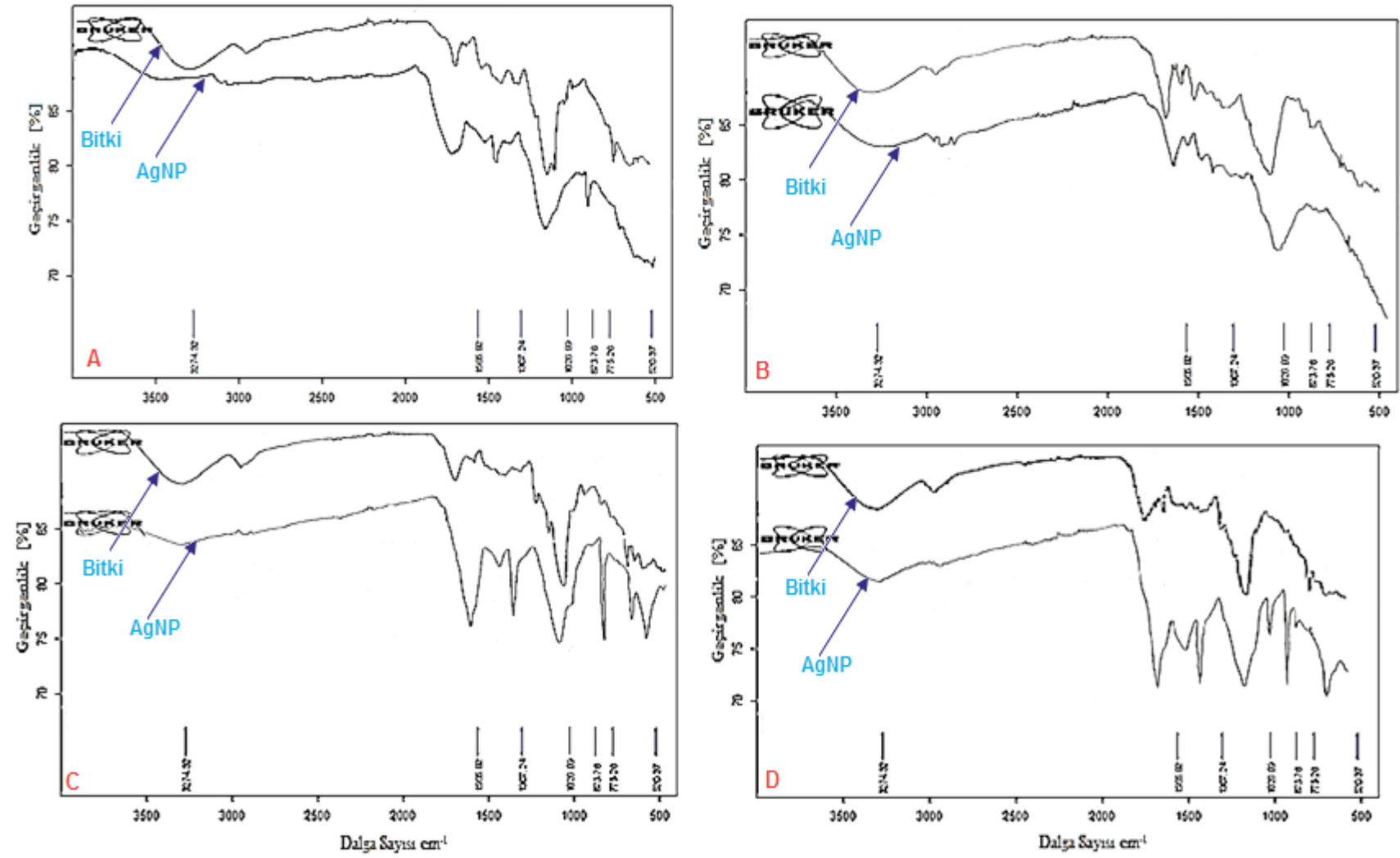

Şekil 2. A)Keçiboynuzu, AgNPs B) Tarçın, AgNPs C)Zencefil, AgNPs D)Zerdeçal, AgNPs FTIR Spektrumları.

Gümüş (Ag) varlığının tespiti için SEM-EDX analizleri yapılmıştır. SEM görüntüleri nanoparçacık boyutu 1 $\mu$ m’ye büyültülerek çekilmiştir. Şekil 4.' de gösterilmiş olan EDX spektrumunda Ag varlığının yanında Fe, O, Al, Mg gibi elementlerde görülmektedir bunların kullanılan antioksidan bitki özütlerinden geldiği tahmin edilmektedir. 


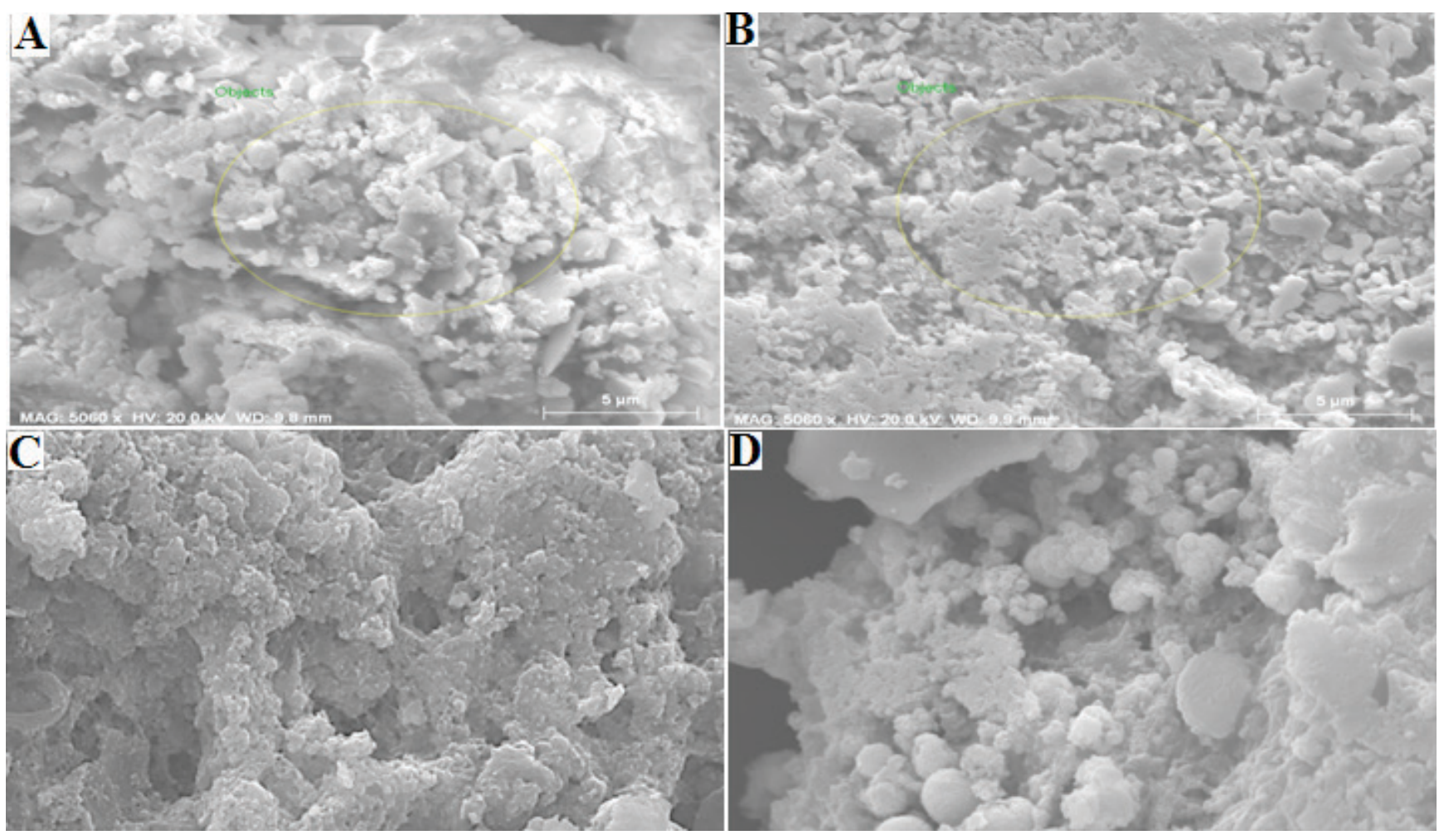

Şekil 3. A) Zencefil-AgNPs B) Zerdeçal-AgNPs C)Tarçın-AgNPs D) Keçiboynuzu-AgNPs SEM Analizi
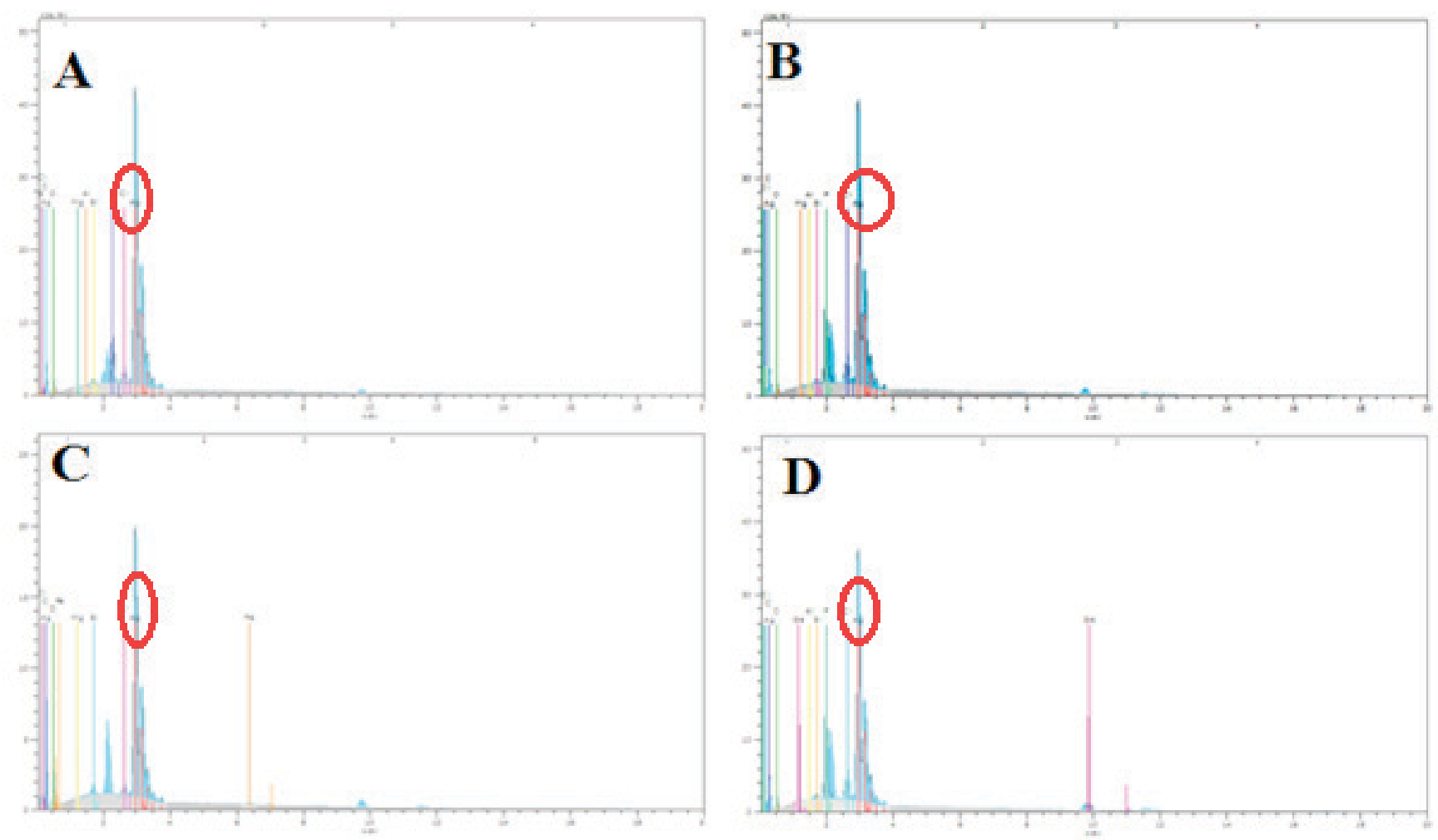

Şekil 4. A) Zencefil-AgNPs B) Zerdeçal-AgNPs C)Tarçın-AgNPs D) Keçiboynuzu-AgNPs EDX Analizi 
SEM-EDX Analizleri sonucunda spektrumda görülen elementler ve oranları aşağıdaki şekildedir.

\begin{tabular}{|c|c|c|c|c|c|c|c|c|c|}
\hline Element & Seri & $\begin{array}{c}\text { unn. } \\
\text { [wt. ş] }\end{array}$ & $\begin{array}{l}\text { C norm. } \\
\text { [wt. s] }\end{array}$ & $\begin{array}{l}\text { C Atom. } \\
\text { [at. } 8 \text { ] }\end{array}$ & Element & Seri & $\begin{array}{l}\text { n. C no } \\
{\left[\mathrm{wt} . *{ }^{\circ}\right]}\end{array}$ & $\begin{array}{l}\text { CIn. C At } \\
{[\mathrm{wt} . * \text { s] }}\end{array}$ & $\begin{array}{l}\text { om. } \\
\text { [at. } \stackrel{*}{*}]\end{array}$ \\
\hline Silver & L-series & 59.66 & 71.12 & 27.24 & silver & L-series & 38.52 & 49.08 & 7.82 \\
\hline Oxygen & K-series & 14.98 & 17.85 & 46.11 & Jxygen & K-series & 18.10 & 27.76 & 48.24 \\
\hline Sulfur & K-series & 3.44 & 4.10 & 5.28 & Jarbon & $\mathrm{K}$-series & 15.60 & 22.12 & 43.35 \\
\hline Carbon & K-series & 4.84 & 5.76 & 19.83 & šlicon & K-series & 0.26 & 0.36 & 0.28 \\
\hline Chlorine & K-series & 0.58 & 0.69 & 0.81 & Thlorine & $\mathrm{K}$-series & 0.10 & 0.14 & 0.08 \\
\hline Aluminium & K-series & 0.03 & 0.03 & 0.05 & lagnesium & K-series & 0.03 & 0.04 & 0.04 \\
\hline Magnesium & K-series & 0.11 & 0.13 & 0.23 & Iron & K-series & 0.36 & 0.50 & 0.19 \\
\hline & Total: & 83.90 & 100.00 & 100.00 & & Total: & 72.98 & 100.00 & 100.00 \\
\hline
\end{tabular}

\subsection{Katalitik Çalışmalar}

Metil Oranj (MO), Metilen Mavisi (MB) ve Rodamin B (RB) boyalarının her bir antioksidan gümüş nanoparçacık ile $25^{\circ} \mathrm{C}$ 'de indirgenmesi gerçekleştirildi. İşlem yukarıda 2.3 'te anlatıldı ğı şekilde yapılarak kısa bir sürede tüm boyaların renksiz hale dönüştüğü gözlendi ve UV sonuçları ile de boyaların indirgendiği doğrulanarak herbir bozunma reaksiyonu için kinetik parametreler (k) hesaplandı. Literatüre k1yasla boyaların bozunması çok kısa sürelerde gerçekleşti ve hesaplanan parametrelere göre de en hizlı bozunmanın tarçın özütü kullanılarak sentezlenen gümüş nanoparçacıkların kullanılmasıyla gerçekleştiği görüldü.

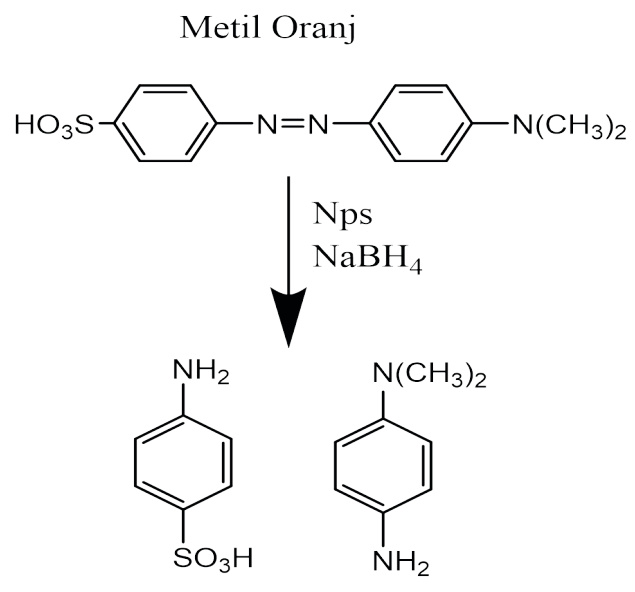

bozunma ürünleri
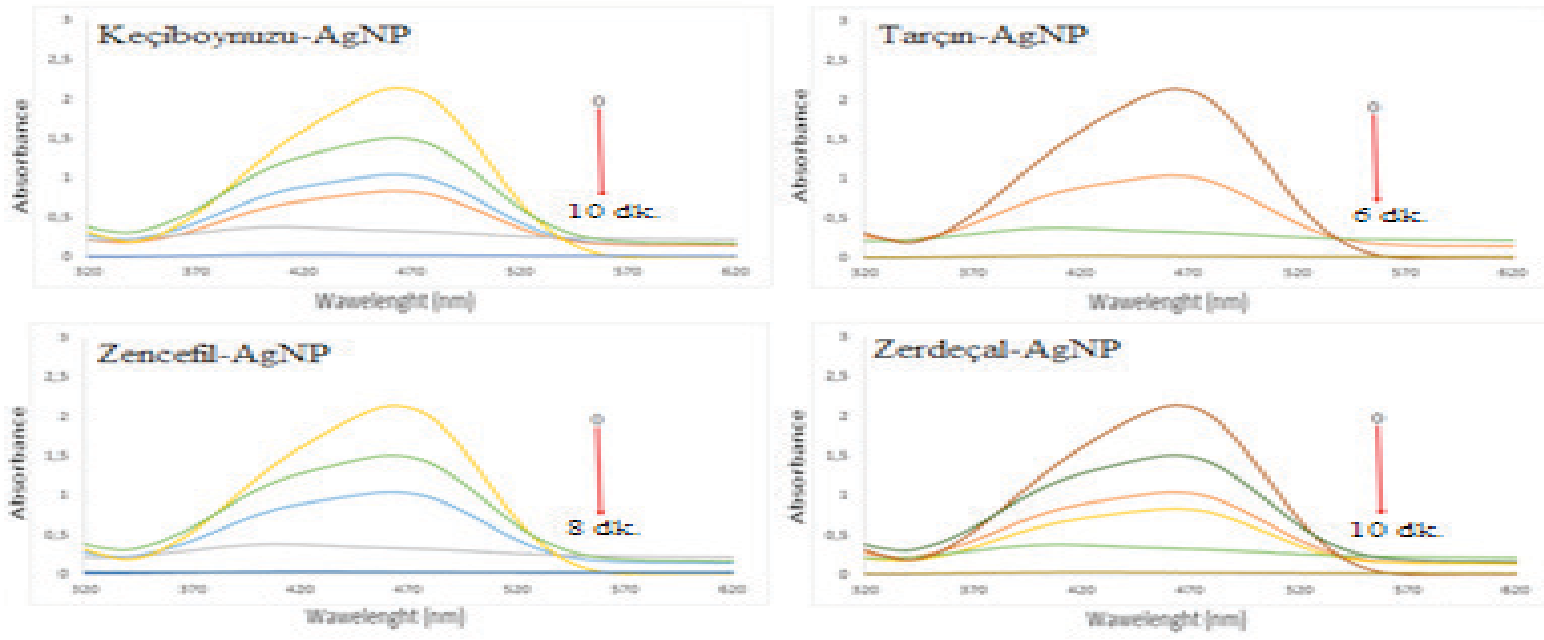


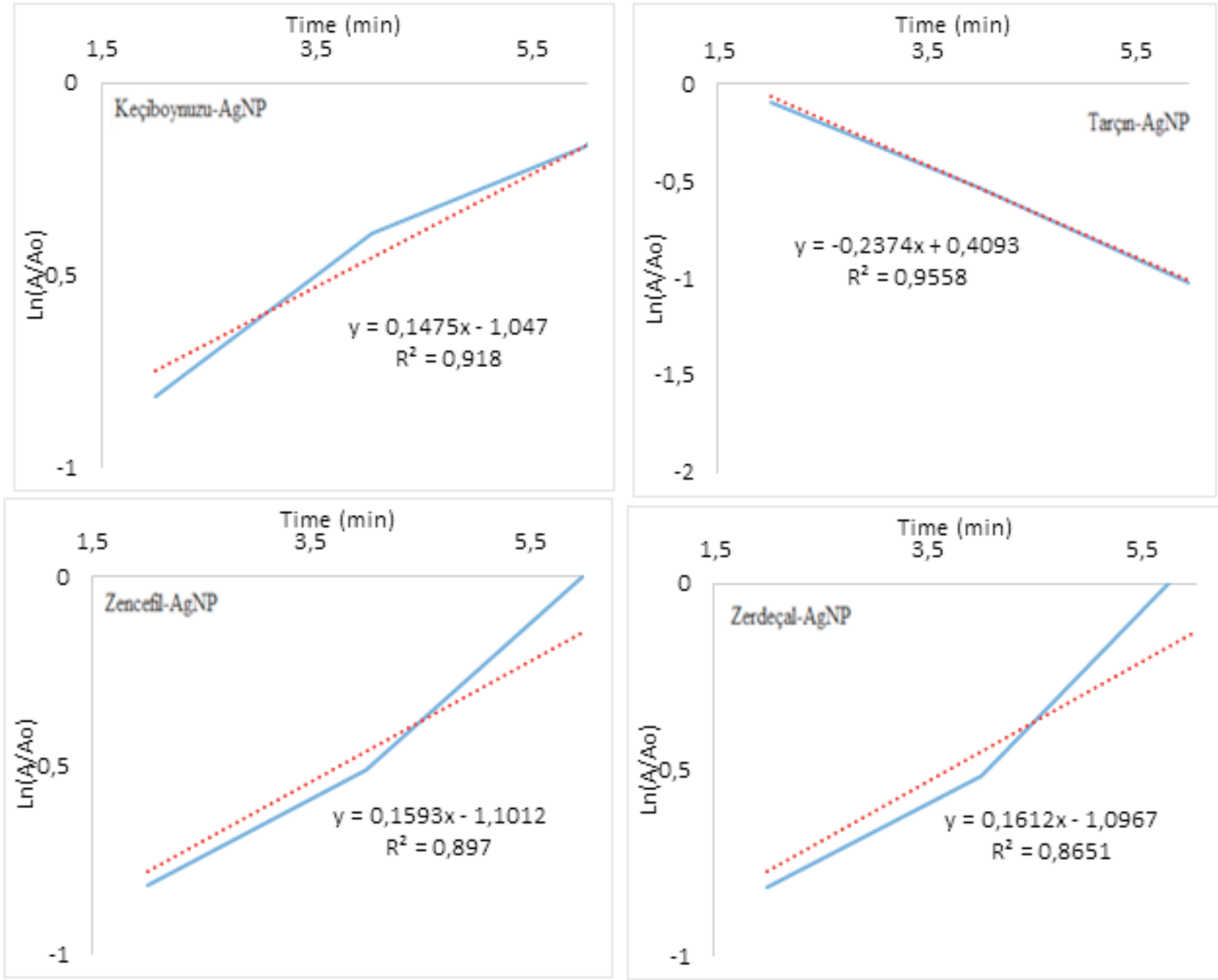

Şekil 5. Metil Oranjın bozunma ürünleri, UV-Vis. Analiz Sonuçları ve Kinetik Hesaplamalar<smiles>CN=c1ccc2nc3ccc(N(C)C)cc3sc-2c1</smiles>

Metilen Mavisi (MB)

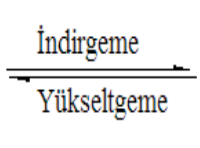

$\mathrm{H}_{3} \mathrm{C}$<smiles>CN(C)c1ccc2c(c1)SC1=CC(=[N+](C)C)C=CC1N2</smiles>

Leosimetilen Mavisi (LMB) 

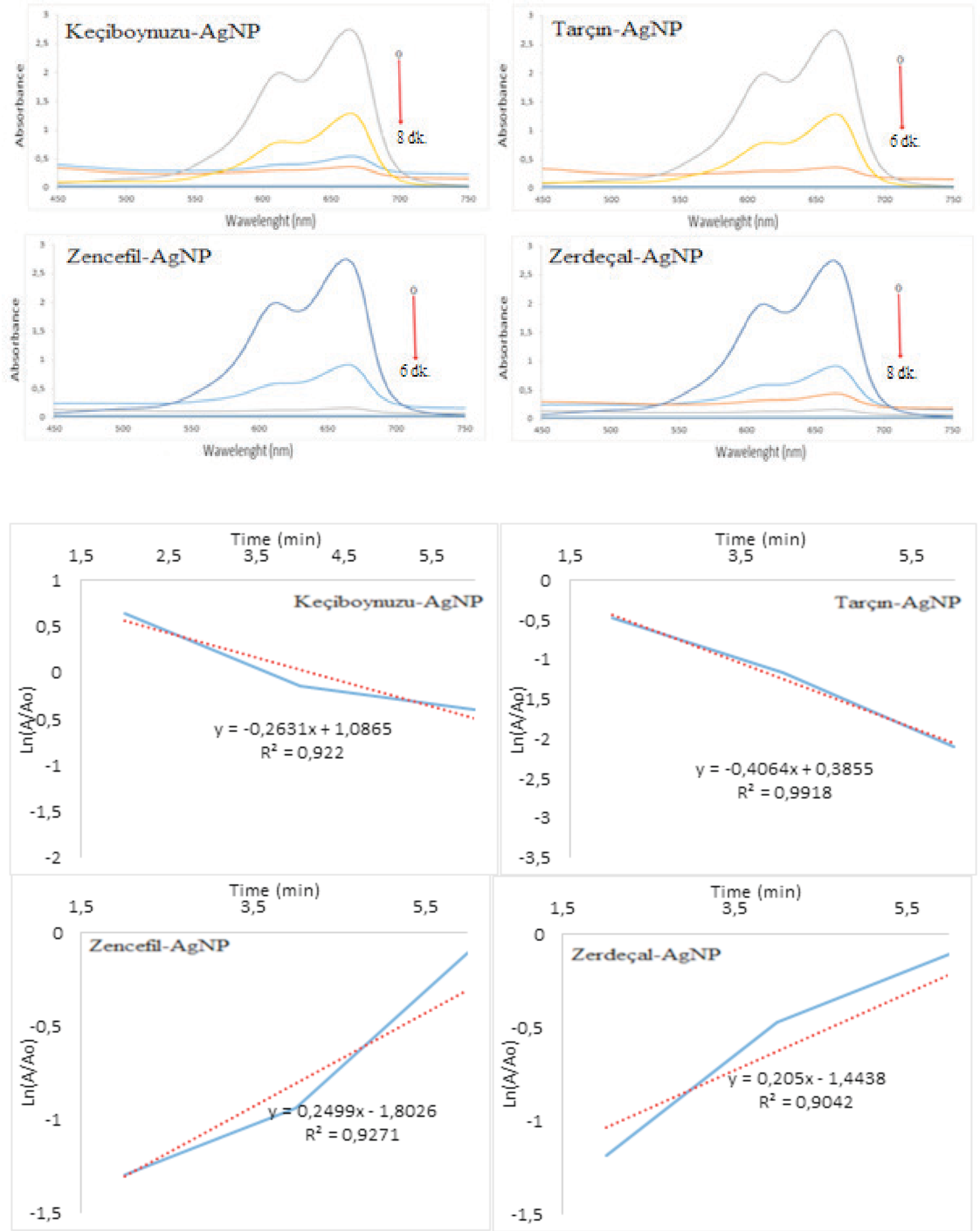

Şekil 6. Metilen Mavisinin bozunma ürünleri, UV-Vis. Analiz Sonuçları ve Kinetik Hesaplamalar 

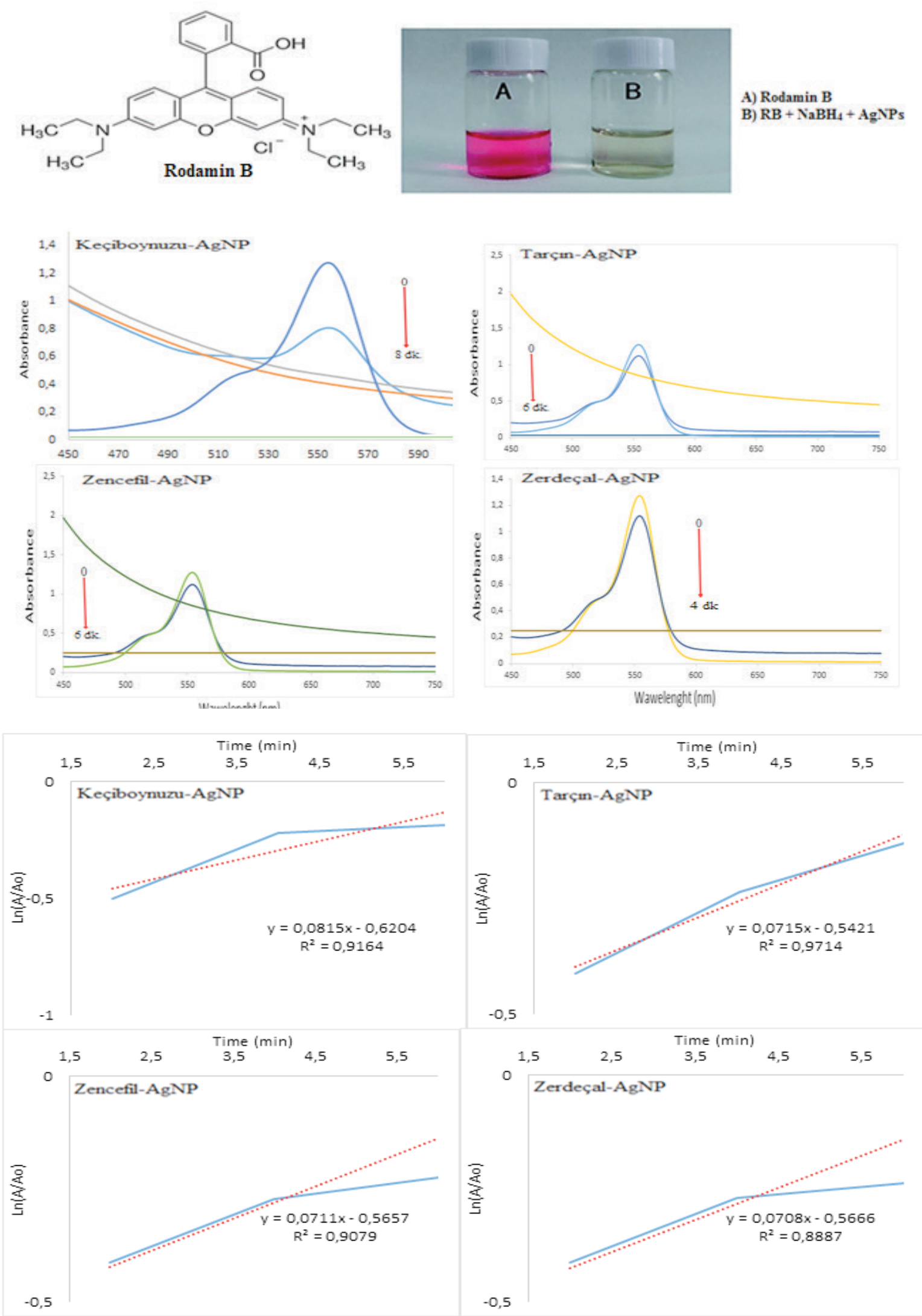

Şekil 7. Rodamin B renk değişimi, UV-Vis. Analiz Sonuçları ve Kinetik Hesaplamalar 


\section{IV.SONUÇLAR}

Antioksidan gümüş nanoparçacıklar, tarçın, keçiboynuzu, zencefil ve zerdeçal özütlerinin indirgeyici ajan olarak kullanılmasıyla kolay, ekonomik ve çevre dostu bir yolla başarıyla hazırlandı. UV-Vis., FTIR, SEM, EDX spektroskopik analizler nanoparçacıkların oluşumunu doğruladı. Nanoparçacıkların büyüklüğünün ve kristal şeklinin belirlenmesi için TEM Analizi yapılacaktır. Bütün antioksidan nanoparçacıkların oda sıcaklığında $\mathrm{NaBH}_{4}$ 'ün varlığında $\mathrm{RB}, \mathrm{MB}$ ve MO'nin bozunma ürünlerine indirgenmesinde katalitik özelliği incelenmiştir.

$\mathrm{NaBH}_{4}$ 'ün varlığında antioksidan gümüş nanoparçacıklar, RB, MB ve MO'nun indirgenmesine yol açan bozunma reaksiyonunu katalize eder; tüm boyalarda absorbans neredeyse sifir olmuştur. Böylece sentezlenen antioksidan gümüş nanoparçacıklar aktivasyon enerjisini azaltarak reaksiyonları katalize eden iyi bir elektron transferi sağladı. Ayrıca, indirgeyici bir madde olarak $\mathrm{NaBH}_{4}, \mathrm{RB}, \mathrm{MB}$ ve MO'yı katalizör olmadan tek başına bu kadar hızlı indirgeyemezdi ve bu da antioksidan gümüş nanoparçacıkların etkinliğini gösterdi. Bu nedenle, antioksidan gümüş nanoparçacıkların varlığında boyaların 6-10 dakikada çok hızlı indirgendiği sonucuna varılmıştır. Bu çalışmada kullanılan antioksidanlar ile farklı metal nanotanecikler sentezlenebilir ve farklı boyaların bozunmasında kataliz etkisi incelenebilir. Ayrıca sentezlenen metal nanoparçacıkların antibakteriyel ve antioksidan özellikleri incelenerek çevre ve sağlık alanında kullanımının da mümkün olabileceği düşünülmektedir.

\section{KAYNAKLAR}

[1] Bar, H., Bhui, D. Kr., Sahoo, G. P., Sarkar, P., Sankar, P. D., \& Misra, A. (2009). Green synthesis of silver nanoparticles using latex of Jatropha curcas. Colloids and Surfaces A: Physicochemical and Engineering Aspects, 339, 134-139.

[2] Flippo, E., Serra, A., Buccolieri, A., \& Manno, D. (2010). Green synthesis of silver nanoparticles with surose and maltose: Morphological and structural characterization. Journal of Non-Crystalline Solids. 356, 344-350.

[3] Dubey, S. P., Lahtinen, M., Sarkka, H., and Sillanpaa, M. (2010). Bioprospective of Sorbusaucuparia leaf extract in development of silver and gold nanocolloids. Colloidsand Surfaces B: Biointerfaces, 80, 26-33.

[4] Rajan, R., MeenaKumari, M., and Philip, D. (2014). Shape tailored green synthesis andcatalytic properties of gold nanocrystals. Spectrochimica Acta Part A: Molecularand Biomolecular Spectroscopy, 118, 793-799.
[5] Navalona, S., Dhakshinamoorthy, A., Alvaroa, M., and Garcia, H. (2016). Metal nanoparticles supported on two-dimensional graphenes as heterogeneous catalysts. Coord Chem Rev. 312, 99-148.

[6] Suvith, V.S., and Philip, D. (2014). Catalytic degradation of methylene blue using biosynthesized gold and silver nanoparticles. Spectrochim Acta A Mol Biomol Spectrosc. 118,526532.

[7] Anandan, S., Satish Kumar, P., Pugazhenthiran, N., Madhavan, J., \& Maruthamuthu, P. (2008). Effect of loaded silver nanoparticles on $\mathrm{TiO}_{2}$ for photocatalytic degradation of acid red 88. Solar Energy Mater Solar Cells 92, 929-937.

[8] Khalilzadeh, M.A., and Borzoo, M. (2016). Green synthesis of silver nanoparticles using onion extract and their application for the preparation of a modified electrode for determination of ascorbic acid. J Food and Drug Anal. 24(4), 796-803.

[9] Wesenberg, D., Kyriakides, I., and Aqathos, S.N. (2003). White-rot fungi and their enzymes for the treatment of industrial dye effuents. Biotechnology Adv. 22(1-2) 161-187.

[10] Arumai, S. D., Mahendiran, D., Senthil, K. R., and Kalilur, R. A. (2018). Garlic, green tea and turmeric extracts-mediated green synthesis of silver nanoparticles: Phytochemical, antioxidant and in vitro cytotoxicity studies. Journal of Photochemistry and Photobiology, B:180, 243-252.

[11] Firdaus, M., Andriana, S., Elvinawati, A.W., Swistoro, E., Ruyani, A., \& Sundaryono, A. (2017). Green synthesis of silver nanoparticles using Carica Papaya fruit extract under sunlight irradiation and their colorimetric detection of mercury ions. Journal of Physics: 012029/1.

[12] Mani, K., Ramasamy, S., Ganesan, A., and Subbaiyan, R., (2017). Evaluation of silver nanoparticles as a comparative study and determination of its effect on Vigna radiata. International Research Journal of Pharmacy, 8(1), 33-40.

[13] Mekkawy, A. I., El-Mokhtar, M. A., Nafady, N. A., Yousef, N., Hamad, M. A., El-Shanawany, S. M., Ibrahim, E. H., \& Elsabahy, M. (2017). In vitro and in vivo evaluation of biologically synthesized silver nanoparticles for topical applications: effect of surface coating and loading into hydrogels. International Journal of Nanomedicine, 12, 759-777.

[14] Selvapriya, V., and Deepa, C., (2017). A novel, comparative study of chemical and green synthesis of silver nanoparticles. Journal of Environmental Nanotechnology, 6(1), 23-26.

[15] Srirangam, G. M., and Rao, K. P., (2017). Synthesis and charcterization of silver nanoparticles from the leaf extract of Malachra capitata (L). Journal of Chemistry,10(1), 46-53.

[16] Noginov M.A., Zhu G., Bahoura M., Adegoke J., Small C., Ritzo B.A., Drachev V.P., \& Shalaev V.M. (2007). The effect of gain and absorption on surface plasmon in metal nanoparticles, Appl. Phys. B,86(3), 455-460. 